\title{
NeW APPROACHES In ASSISTIVE TECHNOLOGIES APPLIED TO ENGINEERING EDUCATION
}

\author{
Andreia Artifice \\ CTS, UNINOVA, DEE/FCT - Universidade Nova de Lisboa, Portugal \\ afva@uninova.pt
}

Manuella Kadar

Computer Science Department, 1 Decembrie 1918 University of Alba Iulia, Romania

mkadar@uab.ro

João Sarraipa

CTS, UNINOVA, DEE/FCT - Universidade Nova de Lisboa, Portugal

jfss@uninova.pt

Ricardo Jardim-Goncalves

CTS, UNINOVA, DEE/FCT - Universidade Nova de Lisboa, Portugal

rg@uninova.pt

\begin{abstract}
The evolution of technology, new learning theories and universal design made the learning process to become more flexible and adaptable. The $21^{\text {st }}$ century society imposes a need for increased cognitive ability, thus students are required to have a combination of academic knowledge and transferable skills. Assistive technologies have been used not only with students with special needs but in an inclusive environment extending it to other students. Students are becoming more aware and sensitive to their own learning preferences and their own learning styles. However, the task of adapting current educational practices and spread information in student environment is still a challenge. This paper proposes new approaches to assistive technology design imposed by the evolution of technology. Students can now choose how to study, where to study and when to study. Underpinning this change, the paper explores how assistive technologies have evolved into learning technologies by taking into consideration the technological pedagogical content knowledge (TPACK) framework and proposing an extension, based on intelligent systems that combines means of bio signals assessment with emotional state evaluation for engineering students.
\end{abstract}

Keywords - assistive technologies, learning technologies, TPACK.

\section{Introduction}

The evolution of technology, new learning theories and universal design made the learning process to become more flexible and adaptable. The $21^{\text {st }}$ century society imposes a need for increased cognitive ability, thus students are required to have a 
combination of academic knowledge and transferable skills. Nowadays, assistive technologies have become more widely used in education to support all students, not only students with special needs. Students are becoming more aware and sensitive to their own learning preferences and their own learning styles. However, although the needs and means of flexible and adaptable learning have been uncovered, a huge task remains regarding adapting current educational practices and disseminating information amongst students. Nowadays, Engineering Education must produce technically excellent and innovative graduates, therefore there is a need to enrich and broaden the means and methods to deliver courses, to better adapt those graduates to the global economy.

This paper proposes new approaches to assistive technology design imposed by the evolution of technology. Students can now choose how to study, where to study and when to study. Underpinning this change, the paper explores how assistive technologies have evolved into learning technologies by taking into consideration the technological pedagogical content knowledge (TPACK) framework. The TPACK framework emphasizes how the connections between teachers' understanding of content, pedagogy, and technology are developed to interact with one another to produce effective teaching. The TPACK framework argues that programs which emphasize the development of knowledge and skills in the above mentioned three areas by an isolated manner are doomed to fail. Thus, effective teacher educational and professional development needs to craft systematic, long-term educational experiences where the participants can engage fruitfully in all the three knowledge bases- content, pedagogy, technology- in an integrated manner.

The hereby proposed architecture and solution named i-TPACK includes software development knowledge and software design strategies to improve the classic TPACK framework. In i-TPACK both students and teachers are involved in a common effort to design new teaching strategies. Such software design strategies are the outcome of thorough studies on students' emotional state, level of attention during classes, face mimics correlated with students' vital signs such as pulse, hart rate, and brain waves. The investigations have been carried out with techniques such as eye tracking, electroencephalography, electrocardiography. On one hand, teachers are involved in assessing students' behaviour during classes and adapt "on the fly" the teaching method to the group's reactions and on the other hand, students can correct their attitude and improve their learning capabilities during classes. Our approach includes the knowledge that teachers acquire when involved in the development of educational software, thus transforming the original concept of TPACK into a smart responsive and corrective system.

This paper is organized as follows: next section is dedicated to literature review. Section 3 entitled "Intelligent Technological Pedagogical Content Knowledge" refers to the design strategy of the smart system. The outcomes are presented in section 4 . Finally, the conclusions are drawn in section 5. 


\section{Literature review}

\subsection{Universal Design Theory}

Universal Design is the design and composition of an environment that is accessible, comprehendible, and usable by as many people as possible independently of their age, size or having any particular ability or disability [1]. Concerning electronic systems, according to the Disability Act 2005 [2], it is considered "any electronics-based process of creating products, services or systems so that may be used by any person". The application of Universal Design theory has contributed to progress in educational context.

According to Pliner et al. [3], Universal Instructional Design (UID), can be seen as "an approach for addressing the diverse learning needs of students enrolled in institutions of higher education". The same authors argue that it allows to expand institutional teaching methodologies to promote equal access to classroom teaching and learning to all students, despite their learning needs.

Regarding pedagogy, technologies such as text-to-speech software, mind maps, audio recording software and note taking technology are instruments that can be adapted to the learner preferences [4].

\subsection{Learning styles and theories}

According to Dunn, a person's learning style "is the way that he or she concentrates on, processes, internalizes, an remembers new and difficult academic information or skills" [5]. Learning styles have been studied from different perspectives. For instance, the Honey-Mumford model refers to four styles [6], [7]: (i) activists - prefer learning by doing, they like group working, consider that repetition is boring, and are characterized by enthusiasm; (ii). reflectors - stand back and observe, they assemble as much information as possible, their strength is data collection and its analysis; (iii) theorists - can adapt their observations into frameworks, and they add learning to existing ones; and (iv) pragmatists - seek and use new ideas, they try to envision the application of new ideas and theories before making a judgment.

The Myers-Briggs model [7], [8] classifies learners in the following categories: 1) extroverts - focus on people, are happy trying things; 2 ) introverts - focus on ideas, tend to think things; 3 ) sensors - focus on facts and procedures, usually are practical; 4) intuitors - are focused on meaning, use imagination and are concept-oriented; 5) thinkers - fundament their decisions on logic and rules; 6) feelers - fundament their decisions on personal and humanistic considerations; 7) judgers - follow agendas, aim closure and completeness; 8) perceivers - tend to adapt to circumstances, they will postpone accomplishment until more is known.

Learning styles and preferences have being studied in practical scenarios. For instance, in a study entitled "Learning Styles an Teaching Styles in College English Teaching", Zhou [9] argues that "an effective means of accommodating these learning 
styles is for teachers to change their own styles and strategies and provide a variety of activities to meet the needs of different learning styles". Consequentially, that increases the probability of a student to be successful. From the practical point of view, the same author, suggests to teachers that want to cover a wide variety of styles to: 1) make liberal use of visuals; 2) assign some repetitive drill exercises; 3) do not spend all time of the class writing on the blackboard; 4) provide explicit instruction in syntax and semantics.

\subsection{SETT (Student - Environment - Task - Tools)}

The SETT framework (Student - Environment - Task - Tools) provides key questions to help make decisions about which specialized tools and related strategies will make a difference for a student's learning. The SETT Framework is a four-part model that encourages collaborative decision-making in stages of assistive technology service design and delivery [10]. The main features of SETT are:

Shared Knowledge: In SETT framework decisions concerning tools is based on the knowledge about the student, the environment and the task.

Collaboration: The SETT Framework is a tool that both requires and supports the collaboration of the people who will be involved in the decision-making and those who will be impacted by the decisions. Collaboration is not only critical for the SETT Framework, it is also critical to gaining the buy-in necessary for effective implementation of any decisions.

Communication: In SETT Framework communication develops in an active and respectful way.

Multiple Perspectives: Everyone involved brings different knowledge, skills, experience, and ideas to the table. Although multiple perspectives can be challenging at times they are critical to the development of the accurate, complete development of shared knowledge. Not only are the multiple professional perspectives important to include, but also those of the student and the parents. This can make the difference between success and lack - off.

Pertinent information: Although there is much information that is pertinent to decision making, there is information that is not relevant. Knowing where to draw the line is important as a moving target.

Flexibility and Patience: When working through the SETT Framework or using any other means of concerns-identification and solution seeking, there is a tendency to suggest possible solutions before the concerns have been adequately identified. When a solution springs to mind, collaborators are urged NOT to voice it until it is time to talk about the tools because when a solution is mentioned, the conversation shifts immediately from concern-identification to determining the worth or lack off worth of the suggested solution. Even when a team member thinks of the "perfect" solution, silent patience is urged. It might not look quite so perfect when all important factors are discussed. 


\section{$2.4 \quad$ TPACK}

Technological Pedagogical Content Knowledge (TPACK) was introduced by Koehler and Mishra in 2005 as a conceptual framework that represents the teachers' knowledge needed to effectively teach with technology [11]. TPACK is rooted in Schulman's work on Pedagogical Content Knowledge (PCK) [12], [13]. The PCK concept allows to qualify the teacher's profession. It refers to the integration of teachers' knowledge with content knowledge, in a way that allows students to understand the subject; TPACK is similar since it adds technological knowledge (TK) as necessary part of teacher's profession [14].

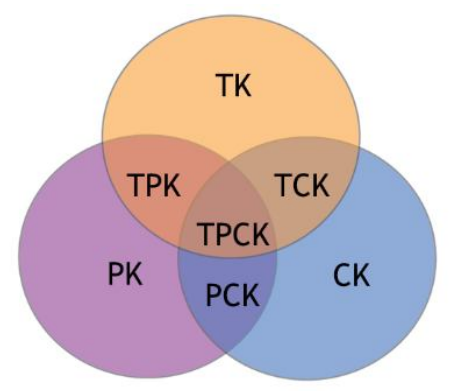

Fig. 1 TPACK [14]

TPACK represents the required knowledge for teachers who need to integrate technology. Specifically, it refers to the interactions between content, pedagogy and technology in order to teach effectively [15] .

Similar frameworks have been developed both independently and directly out of the TPACK framework. Most of them are based upon Shulman's (1986) model of Pedagogical Content Knowledge. Similar frameworks include (but are not limited to): ICT - Related Pedagogical Content Knowledge (ICTRelated PCK); Knowledge of Educational Technology; Technological Content Knowledge; Electronic Pedagogical Content Knowledge (ePCK); and Technological Pedagogical Content Knowledge Web (TPCK-W) [16], [17], [18], [19], [20].

The TPACK framework has contributed to the teacher's education and professional development. According to the TPACK framework, effective teacher educational and professional development occur in an integrated manner based on the knowledge bases [15]. The same authors argue that a limitation of TPACK framework is a neutral position concerning broader goals of education.

The $21^{\text {st }}$ century requires cognitive skills, necessary for successful learning and achievement, such as critical thinking, problem solving, job and life skills, and synthesis. Additionally, interpersonal skills are required, for instance communication and collaboration [21]. In that context, Mishra et al. [22] proposes seven cognitive tools within TPACK, that are necessary for the new millennium: perceiving, patterning, abstracting, embodied thinking, modelling, playing, and synthesizing. 


\section{Intelligent Technological Pedagogical Content Knowledge (i- TPACK)}

The Intelligent Technological Pedagogical Content Knowledge (i-TPACK) framework promotes the incorporation of software development knowledge and software design strategies as an extension of the TPACK. The system was designed and tested for Engineering Education as the teaching methods focused on engineering processes to define and solve problems using scientific, technical, and professional knowledge bases. Both students and teachers have been involved in the studies.

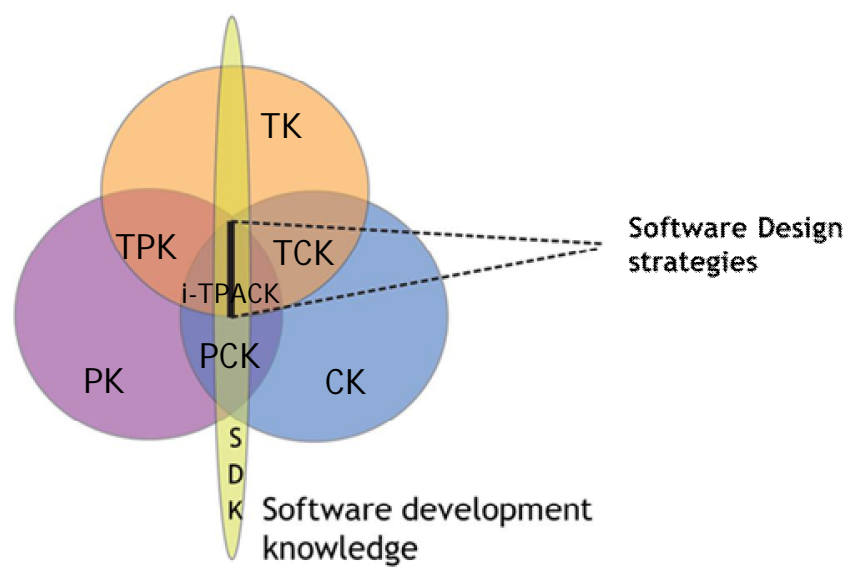

Fig. 2 Architecture of i-TPACK

The main goal of the research was to study means and to design inclusive technologies to fight student's dropout. Keeping in mind the principles of TPACK framework we propose a system that infers attention analytics based on bio signals of the students. Bio signals are provided by wearable devices for brain waves and heart rates measurements. These are validation methods of the proposed architecture and teaching approach. A case study with scenario is presented for music-based learning. The scope of this analysis is to validate the student's attention level with background music versus no music during a learning process. To achieve this goal, we have evaluated the solution using neuroscience and emotion detection techniques to assess the perception and understanding for personalized learning. In this study the adopted methods explore the hypothesis that a person's physiological state can wield adequate sensorial stimulation to provide diverse levels of information. The solution uses collected data to build a user's musical playlists that tries to match a psychological state with the stimuli evoked by the music that the student is listening to. From that matching, it is possible to improve a person's wellbeing by providing the most adequate music to lift the emotional state of that person. 


\section{Outcomes}

Taking into consideration our approach and the results of the study it has been confirmed that it is possible to improve a person's learning capability with the most suitable music to that person in that moment. The benefits are obvious as the person feels better, will perform better, especially when referring to cognitive functions as studying and learning new subjects. Figure 3 presents the application scenario.

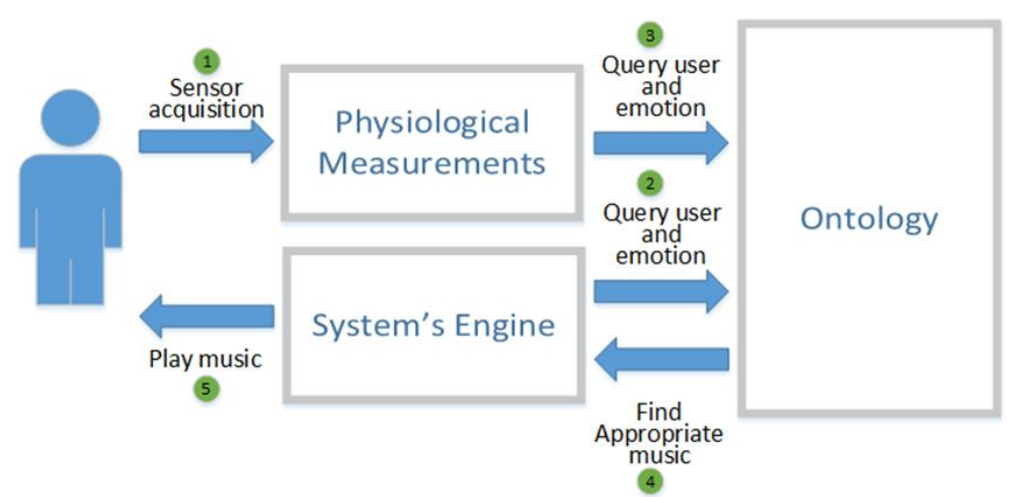

Fig. 3 Application scenario

The main application scenario consists of the appropriated environment for the inclusion of a smart system that allows to suggest the appropriated music concerning the person's cognitive state based on bio signals. Such technological environment includes sensor acquisition, specifically electrocardiogram (EKG) and electroencephalogram (EEG); a system engine that analysis and recommends the music and stores an ontology in which appropriated knowledge is represented.

Students attention is an important aspect concerning the learning performance and it is related to the person's physiological activity [23]. A physiological state is associated with specific physiological signals that can be captured through technological devices, for instance the ECG and EEG.

Next, will be summarized the results of the experiments that have been performed to develop the scenario. Specifically, the experiments have focused on attention studies in the presence of music as means to improve teaching environments.

\subsection{Analysis of attention with EEG}

EEG can perform as an indicator of the level of attention. It can be used to measure the attention spans of students, to help them to improve their learning experience. That indicators are performed from raw signals captured from sensors. EEG is a viable method for determining whether students are attentive.

EEG allows to measure directly the internal state, recording electrical activity of the entire scalp. Furthermore, it can detect changes in real-time. 
In the experiment performed, EEG measurement of attention training and assessment system include: functions of data acquisition, signal processing, data analysis, data presentation. Five participants were included in the study. It was used the headset Mindwave connected to the Lucid Scribe software. The computerized Prague test, created by Psycho-technical Institute in Prague, was selected for this study to measure distributed attention of students. The aim of the experiment was to investigate how useful Neurosky Mindwave is in measuring attention levels [24].

The measurements of the MindWave are outlined as follows: raw signal, EEG power spectrum, eSense meters for attention and meditation. The eSense Attention meter indicates the intensity of the user's level of mental 'focus' or 'attention' to determine levels of concentration.

Results achieved by the participants in the test are presented in table 1. Concerning distributed attention: 3 participants scored excellent, 1 scored good, and 1 sufficient.

Table 1. Results achieved by participants in the experiment.

\begin{tabular}{|l|c|c|c|c|c|c|c|c|}
\hline No & Students & Age & Gender & $\begin{array}{c}\text { First } \\
\mathbf{4} \text { min }\end{array}$ & $\begin{array}{c}\text { Second } \\
\mathbf{4} \text { min }\end{array}$ & $\begin{array}{c}\text { Third } \\
\mathbf{4} \text { min }\end{array}$ & $\begin{array}{c}\text { Forth } \\
\mathbf{4} \text { min }\end{array}$ & Total \\
\hline 1 & M.M.M. & 20 & F & 15 & 28 & 25 & 14 & 82 \\
\hline 2 & C. D. I. & 20 & F & 17 & 16 & 18 & 19 & 70 \\
\hline 3 & I.T. & 20 & F & 4 & 4 & 8 & 7 & 23 \\
\hline 4 & L.S. & 21 & M & 12 & 26 & 25 & 24 & 87 \\
\hline 5 & S.I.R. & 21 & F & 18 & 15 & 20 & 29 & 82 \\
\hline
\end{tabular}

Concerning attention levels results are presented in table 2 . The average values are between 7.3 and 67.5 .

Table 2. Levels of attention achieved by participants in the experiment.

\begin{tabular}{|l|c|c|c|c|c|c|c|c|}
\hline No & Students & Age & Gender & $\begin{array}{c}\text { First } \\
\mathbf{4} \text { min }\end{array}$ & $\begin{array}{c}\text { Second } \\
\mathbf{4} \text { min }\end{array}$ & $\begin{array}{c}\text { Third } \\
\mathbf{4} \text { min }\end{array}$ & $\begin{array}{c}\text { Forth } \\
\mathbf{4} \text { min }\end{array}$ & Total \\
\hline 1 & M.M.M. & 20 & F & 15 & 28 & 25 & 14 & 82 \\
\hline 2 & C. D. I. & 20 & F & 17 & 16 & 18 & 19 & 70 \\
\hline 3 & I.T. & 20 & F & 4 & 4 & 8 & 7 & 23 \\
\hline 4 & L.S. & 21 & M & 12 & 26 & 25 & 24 & 87 \\
\hline 5 & S.I.R. & 21 & F & 18 & 15 & 20 & 29 & 82 \\
\hline
\end{tabular}

\subsection{Analysis of attention with ECG}

To analyse a person's attention during cognitive tasks in the presence of music, a set of experiments has been performed. The main goal of the experiments was to correlate a person's attention with features extracted from ECG signal.

First, a prospective study was developed in the context of eLearning in which participants performed the task of attending a course, including learning and test 
phases, in the presence vs. absence of classical music [25]. At the same time ECG measurements were recorded for further analysis. In the referred analysis it was computed the Heart Rate Variability, i.e. "the amount of heart rate fluctuations between the mean heart rate" [26] of the ECG signal and analysed the Low Frequency (LF) and Hight Frequency (HF) features, as can be seen in the figures 4 and 5 .

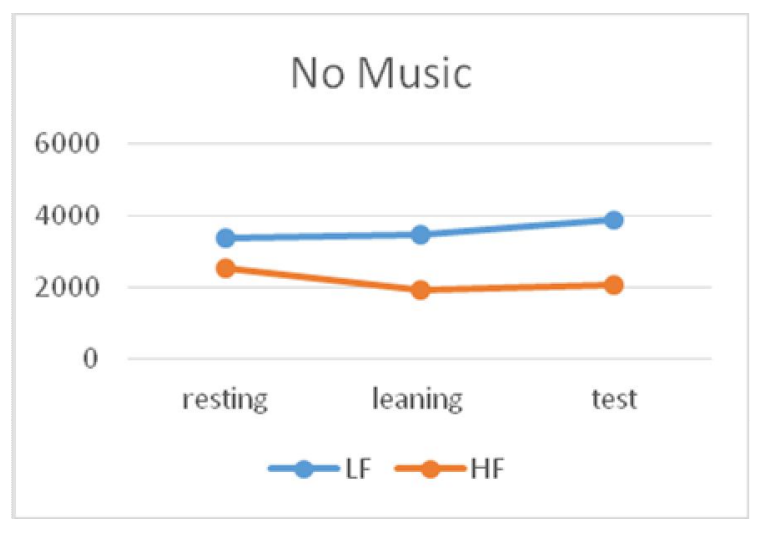

Fig. 4 Average $\mathrm{LF}\left(\mathrm{ms}^{2}\right)$ and $\mathrm{HF}\left(\mathrm{ms}^{2}\right)$ for eLearning course with no music [25].

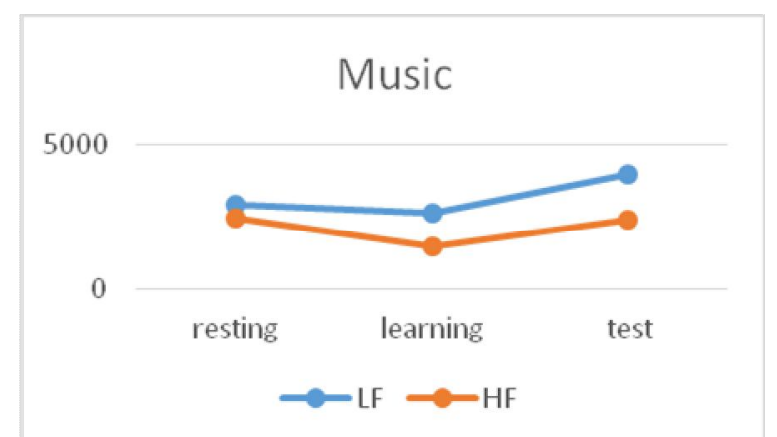

Fig. 5 Average $\mathrm{LF}\left(\mathrm{ms}^{2}\right)$ and $\mathrm{HF}\left(\mathrm{ms}^{2}\right)$ for eLearning course music [25].

The results revealed, according to a study [27], that LF and HF have a decrease when attention decreases. Additionally, the study revealed that the participants were more attentive when they performed the task with classical background music.

The study allowed us to determine the relationship between attention and Low Frequency and High Frequency Hear Rate Variability features extracted from ECG signal in eLearning environment with and without classical music. The outcomes allowed us to conclude that there is a correlation between student's attention and the Heart Rate Variability features (LF and HF) extracted from ECG signal.

The second experiment was developed to test in more detail the applied methodology. The chosen environment was the execution of an immersive cognitive task, namely playing a game. The task was performed with classical music vs. 
annoying music. Results have been corroborated and shown to be aligned with the first performed study.

\section{Conclusions}

As a general conclusion, technology can be interpreted as the set of theories and techniques allowing the practical use of scientific knowledge in a framework as TPACK. The proposed smart system collects and integrates several bio-signals from the user. It is an innovative solution in the student's dropout scenario since it can suggest automatically the appropriated music to the student to improve his emotional state. It also considers the knowledge that teachers acquire when involved in the development of software for education.

The above-mentioned example can be used by students even beyond the teaching environment so that they can feel better and be extrapolated to other professionals, like the teachers, thus promoting other person's wellbeing either in the teaching environment or in other life circumstances.

\section{Acknowledgment}

The authors acknowledge the European Commission for its support and partial funding and the partners of the research project from ERASMUS+: Higher Education - International Capacity Building - ACACIA - Project reference number - 561754EPP-1-2015-1-CO-EPKA2-CBHE-JP, (http://acacia.digital).

\section{$7 \quad$ References}

[1] "Definition and overview | Centre for Excellence in Universal Design." [Online]. Available: http://universaldesign.ie/What-is-UniversalDesign/Definition-and-Overview/. [Accessed: 17-May-2018].

[2] O. of the H. of the O. H. S. D. B. Office, "Disability Act 2005." [Online]. Available: http://www.achtanna.ie/en.act.2005.0014.7.html. [Accessed: 17May-2018].

[3] S. M. Pliner and J. R. Johnson, "Historical, theoretical, and foundational principles of universal instructional design in higher education," Equity Excell. Educ., vol. 37, no. 2, pp. 105-113, 2004.

[4] M. Goldrick, T. Stevns, and L. B. Christensen, "The Use of Assistive Technologies as Learning Technologies to Facilitate Flexible Learning in Higher Education,” LNCS, vol. 8548, pp. 342-349, 2014.

[5] M. F. Shaughnessy, "An interview with Rita Dunn about learning styles," Clear. House, vol. 71, no. 3, pp. 141-145, 1998. 
[6] P. Honey and A. Mumford, Manual of Learning Styles, 2nd ed. London: P. Honey, 1986.

[7] A. Pritchard, Ways of learning. 2009.

[8] I. Myers and P. Myers, "GIFTS DIFFERNING: Understanding Personality." Nicholas Brealey Publishing, 2010.

[9] M. Zhou, "Learning Styles and Teaching Styles in College English Teaching," Int. Educ. Stud., vol. 4, no. 1, pp. 73-77, 2011.

[10] J. S. Zabala, "Using the SETT framework to level the learning field for students with disabilities," Retrieved August, vol. 10, no. Revised, p. 2010, 2005.

[11] M. C. Herring, M. J. Koehler, and P. Mishra, Handbook of technological pedagogical content knowledge (TPACK) for educators. Routhedge, 2016.

[12] L. Shulman, "Knowledge and teaching: Foundations of the new reform," Harv. Educ. Rev., pp. 1-23, 1987.

[13] L. E. Shulman, "Those who understand: knowledgeK growth in teaching," Educ. Res., vol. 15, no. 2, pp. 4-14, 1986.

[14] J. Voogt, P. Fisser, J. Tondeur, and B. Johan van Braak, "Using Theoretical Perspectives in Developing Understanding of TPACK."

[15] M. J. Koehler, P. Mishra, K. Kereluik, T. S. Shin, and C. R. Graham, "The Technological Pedagogical Content Knowledge Framework," in Handbook of Research on Educational Communications and Technology, 2014.

[16] C. Angeli, N. Valanides, "Pre-service elementary teachers asinformation and communication technology designers: An instructionalsystems design model based on an expanded view of pedagogical content knowledge", in Journal of Computer Assisted Learning , 21 (4), 292-302, 2005.

[17] C. Franklin, "Teacher preparation as a critical factor in elementary teachers: Use of computers" In R. Carlsen, N. Davis, J. Price., R. Weber, \& Dl Willis (Eds.), Society for Information Technology and Teacher Education Annual, pp. 4994-4999). Norfolk, VA: Association for the Advancement of Computing in Education, 2004.

[18] M.H. Lee, C.C. Tsai, "Exploring teachers' perceived self efficacy and technological pedagogical content knowledge with respect to educational use of the World Wide Web" in Instructional Science, 38 (1), pp. 1-21, 2010.

[19] J. Margerum-Lays, R.W. Marx, "Teacher knowledge of educational technology: A case study of student/mentor teacher pairs" In Y. Zhao (Ed.), What should teachers know about technology? Perspectives and practices, pp. 123-159, Greenwich, CO, 2003.

[20] S. Slough, M. Connell, "De fi ning technology and its natural corollary, technological content knowledge (TCK)." In C. Crawford et al. (Eds.), Proceedings of Society for Information Technology and Teacher Education International Conference, pp. 1053-1059, Chesapeake, VA: AACE, 2006.

[21] P. Mishra and K. Kereluik, "What 21 Century Learning? A review and a synthesis," in Society for Information Technology \& Teacher Education International Conference, 2011, pp. 2201-3312.

[22] P. Mishra, M. J. Koehler, and D. Henriksen, "The 7 trans-disciplinary habits 
of mind - Extending TPACK framework towards 21st Century Learning," Educ. Technol., pp. 22-28, 2011.

[23] R. A. Cohen, Y. A. Sparling-Cohen, and B. F. O'Donnell, The Neuropsychology of Attention. New York: Plenum Press, 1993.

[24] M. Kadar, P. N. Borza, M. Romanca, D. Iordăchescu, T. Iordăchescu, "Smart Testing Environment for the Evaluation of Students' Attention", in Interaction Design and Architecture(s) Journal - IxD\&A, N.32, pp. 205-217, 2017.

[25] A. Artífice, F. Ferreira, E. Marcelino-Jesus, J. Sarraipa, and R. JardimGonçalves, "Student's attention improvement supported by physiological measurements analysis," in IFIP Advances in Information and Communication Technology, 2017.

[26] C. M. van Ravenswaaij-Arts, C. M. Collee, J. C. Hopman, G. B. Stoelinga, and H. P. van Geijn, "Heart Rate Variability," Ann. Intern. Med., vol. 118, no. 6, pp. 436-447, 1993.

[27] K. Tripathi, C. Mukundan, and T. L. Mathew, "Attentional modulation of heart rate variability (HRV) during execution of PC based cognitive tasks," Ind J Aerosp. Med, vol. 47, no. 1, pp. 1-10, 2003. 